\title{
Supplementary Material for "Evaluating the simulated radiative forcings, aerosol properties and stratospheric warmings from the 1963 Agung, 1982 El Chichon and 1991 Mt Pinatubo volcanic aerosol clouds"
}

S. S. Dhomse ${ }^{1,2}$, G. W. Mann ${ }^{1,3}$, J.-C. Antuna Marrero ${ }^{4}$, S. Shallcross ${ }^{1}$, M. P. Chipperfield ${ }^{1,2}$, K. S. Carslaw $^{1}$, L. Marshall ${ }^{1,5}$, N. L. Abraham ${ }^{5}$, and C. E. Johnson ${ }^{6}$

${ }^{1}$ School of Earth and Environment, University of Leeds, Leeds, UK

${ }^{2}$ National Centre for Earth Observation, University of Leeds, Leeds, UK

${ }^{3}$ National Centre for Atmospheric Science (NCAS-Climate), University of Leeds, Leeds, UK

${ }^{4}$ Department of Theoretical Physics, Atomics and Optics, University of Valladolid, Valladolid, Spain

${ }^{5}$ Department of Chemistry, University of Cambridge, Cambridge, UK

${ }^{6}$ Earth System science and climate mitigation, Met Office, Exeter, UK

Correspondence: Sandip S. Dhomse ( s.s.dhomse@leeds.ac.uk), Graham Mann (g.w.mann@leeds.ac.uk)

\section{Converting Backscatter Ratio to Extinction}

The wavelength exponent and aerosol extinction factor are necessary coefficients for calculating extinction from the backscatter ratio. These are obtained from Figures 2 and 4 in Jäger and Deshler (2003a) for four monthly averages (note the published correction for Figure 2 in ?). As these coefficients are not available for the time of the Agung eruption, we use values for March 1992-October 1993, which represent values from 10 months after the 1991 Mount Pinatubo eruption. As the coefficients are derived considering the temporal evolution of the particle size distribution (PSD), we assume a similar temporal evolution of the Agung PSD here to the period starting 10 months following the Pinatubo eruption.

The calculation for molecular backscatter is from Vega et al. (2017):

$$
\beta_{\text {Rayleigh }(\lambda, z, \theta)}=2.938 \times 10^{-32} \frac{P_{(z)}}{T_{(z)}} \cdot \frac{1}{\lambda^{4.0117}}\left(m^{-1} s r^{-1}\right)
$$

where $\mathrm{P}$ is pressure (hPa), T is temperature (K), $\mathrm{z}$ is altitude (m), $\lambda$ is wavelength (m) and $\beta_{\text {Rayleigh }}$ is the backscatter coefficient (angular).

The backscatter ratio $(B S R)$ is defined as:

$$
B S R=\frac{\beta_{\text {mol }}+\beta_{\text {aer }}}{\beta_{\text {mol }}}
$$

where $\beta_{m o l}$ and $\beta_{a e r}$ are molecular and aerosol backscatter, respectively.

In general, the steps used to convert the lidar backscatter to extinction are as follows: 
1. Calculate molecular backscatter for MLO using $\beta_{\text {Rayleigh }}$ for a given pressure. Here, we use values from US standard atmosphere (Table S1).

2. Calculate the aerosol backscatter $\left(\beta_{a e r}\right)$ using:

$$
\beta_{a e r 694}=(B S R-1) \times \beta_{m o l 694}
$$

where, $\beta a e r 694$ and $\beta m o l 694$ are aerosol and molecular backscatter at $694 \mathrm{~nm}$, respectively.

3. Convert aerosol backscatter at $694 \mathrm{~nm}$ to $532 \mathrm{~nm}$ using:

$$
\beta_{a e r 532}=\left(\frac{694}{532}\right)^{k b} \times \beta_{\text {aer } 694}
$$

where $\beta_{\text {aer532 }}$ is aerosol backscatter at $532 \mathrm{~nm}$ or, more generally, from wavelength $\lambda_{2}$ to $\lambda_{1}$ :

$$
\beta \lambda_{1}=\left(\frac{\lambda_{2}}{\lambda_{1}}\right)^{k b} \times \beta \lambda_{2}
$$

4. Calculate extinction at $532 \mathrm{~nm}$ using:

$$
E X T_{532}=\beta_{\text {aer } 532} \times k e
$$

where $E X T_{532}$ is the aerosol extinction at $532 \mathrm{~nm}$ and $k e$ is the aerosol extinction factor.

Table S1. Standard atmosphere values of pressure, altitude and temperature.

\begin{tabular}{llll}
\hline $\begin{array}{l}\text { Pressure } \\
(\mathrm{hPa})\end{array}$ & $\begin{array}{l}\text { Altitude } \\
(\mathrm{m})\end{array}$ & $\begin{array}{l}\text { Temperature } \\
\left({ }^{\circ} \mathrm{C}\right)\end{array}$ & $\begin{array}{l}\text { Temperature } \\
(\mathrm{K})\end{array}$ \\
\hline \hline 120.4 & 15000 & -56.5 & 216.65 \\
47.5 & 20900 & -55.6 & 217.55 \\
25.1 & 25000 & -51.5 & 221.65 \\
\hline
\end{tabular}


Bauman, J. J., Russell, P. B., Geller, M. A., and Hamill, P.: A stratospheric aerosol climatology from SAGE II and CLAES measurements: 1. Methodology, Journal of Geophysical Research D: Atmospheres, 108, n/a-n/a, https://doi.org/10.1029/2002JD002993, http://doi.wiley. com/10.1029/2002JD002992http://doi.wiley.com/10.1029/2002JD002993http://www.agu.org/pubs/crossref/2003/2002JD002993.shtml, 2003.

35 Jäger, H. and Deshler, T.: Lidar backscatter to extinction, mass and area conversions for stratospheric aerosols based on midlatitude balloonborne size distribution measurements, Geophysical Research Letters, 30, 35-1-35-4, https://doi.org/10.1029/2003GL017189, http://doi.wiley.com/10.1029/2003GL017189, 2003a.

Jäger, H. and Deshler, T.: Correction to "Lidar backscatter to extinction, mass and area conversions for stratospheric aerosols based on midlatitude balloonborne size distribution measurements”, Geophysical Research Letters, 30, https://doi.org/10.1029/2003GL017189, https://agupubs.onlinelibrary.wiley.com/doi/abs/10.1029/2003GL017189, 2003b.

Thomason, L. W., Ernest, N., Millán, L., Rieger, L., Bourassa, A., Vernier, J.-P., Manney, G., Luo, B., Arfeuille, F., and Peter, T.: A global space-based stratospheric aerosol climatology: 1979-2016, Earth System Science Data, 10, 469-492, 2018.

Vega, A. R., Carlos, J., and Marrero, A.: Standardizing the determination of the molecular backscatter coefficient profiles for LALINET lidar stations using ERA-Interim Reanalysis Estandarización en la determinación de los perfiles del coeficiente de retrodispersión molecular para las estaciones, www.sedoptica.es Opt. Pura Apl, 50, 103-114, https://doi.org/10.7149/OPA.50.1.49013, https://doi.org/10.7149/OPA. 47.2.109, 2017. 

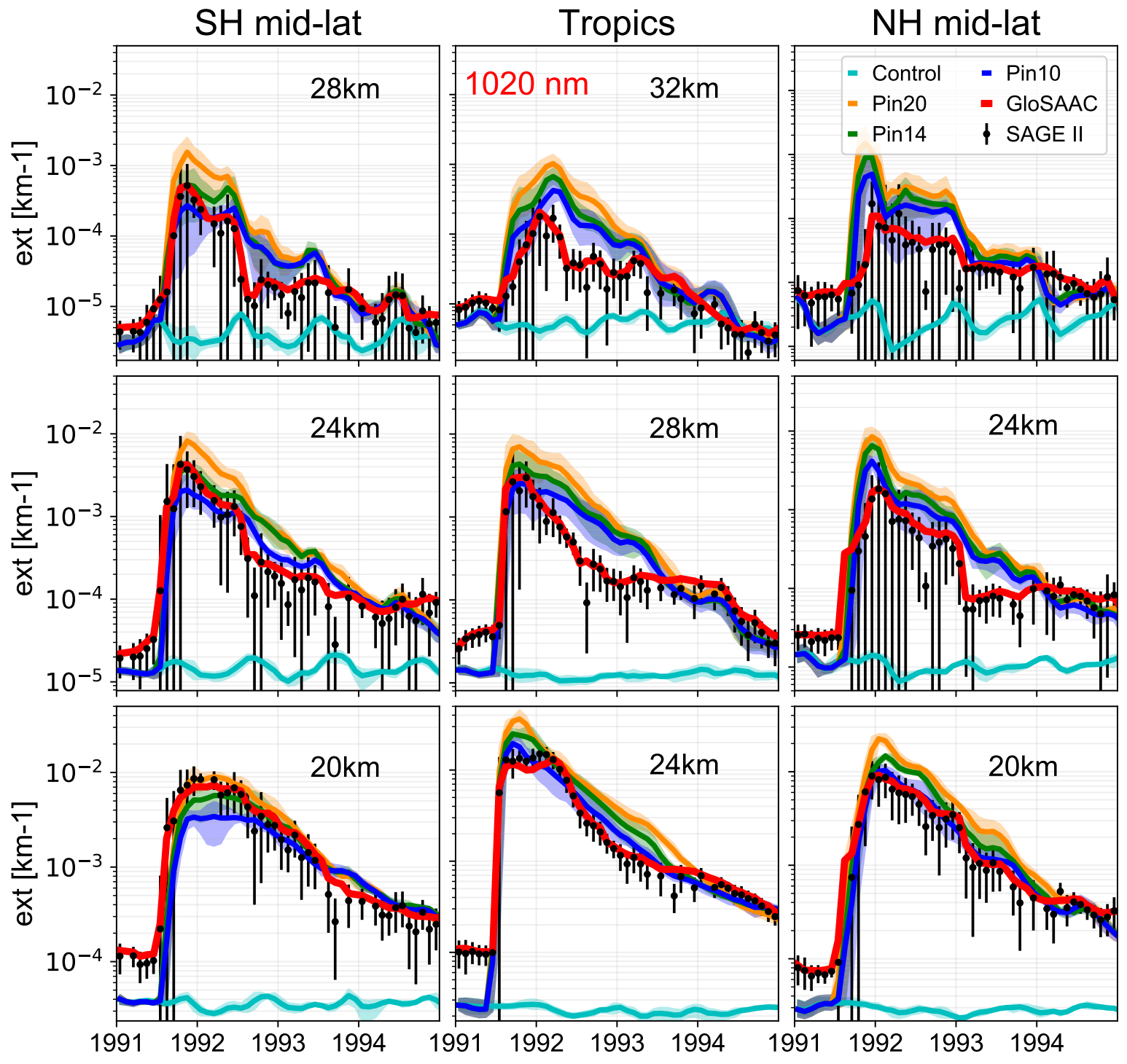

Figure S1. Ensemble mean extinctions (1020 nm) from simulations Pin00 (aqua), Pin10 (blue), Pin14 (green), and Pin20 (orange). The shaded regions indicate the variability among ensemble members. Extinctions for $\mathrm{SH}$ mid-latitudes $\left(35^{\circ} \mathrm{S}-60^{\circ} \mathrm{S}\right)$, tropics $\left(20^{\circ} \mathrm{S}-20^{\circ} \mathrm{N}\right)$, and $\mathrm{NH}$ mid-latitudes $\left(35^{\circ} \mathrm{N}-60^{\circ} \mathrm{N}\right)$ are shown in left, middle and right panels, respectively. Mid-latitude extinctions are shown for 20 , 24 and $28 \mathrm{~km}$, whereas tropical profiles are shown for 24, 28 and $32 \mathrm{~km}$. Monthly mean extinction from SAGE II v7.2 measurements for a given latitude band are shown with black filled circles and vertical lines indicate standard deviation from all the measurements for a given month. Gap-filled extinctions from the GLoSSAC dataset (Thomason et al., 2418) are shown with a red line. 


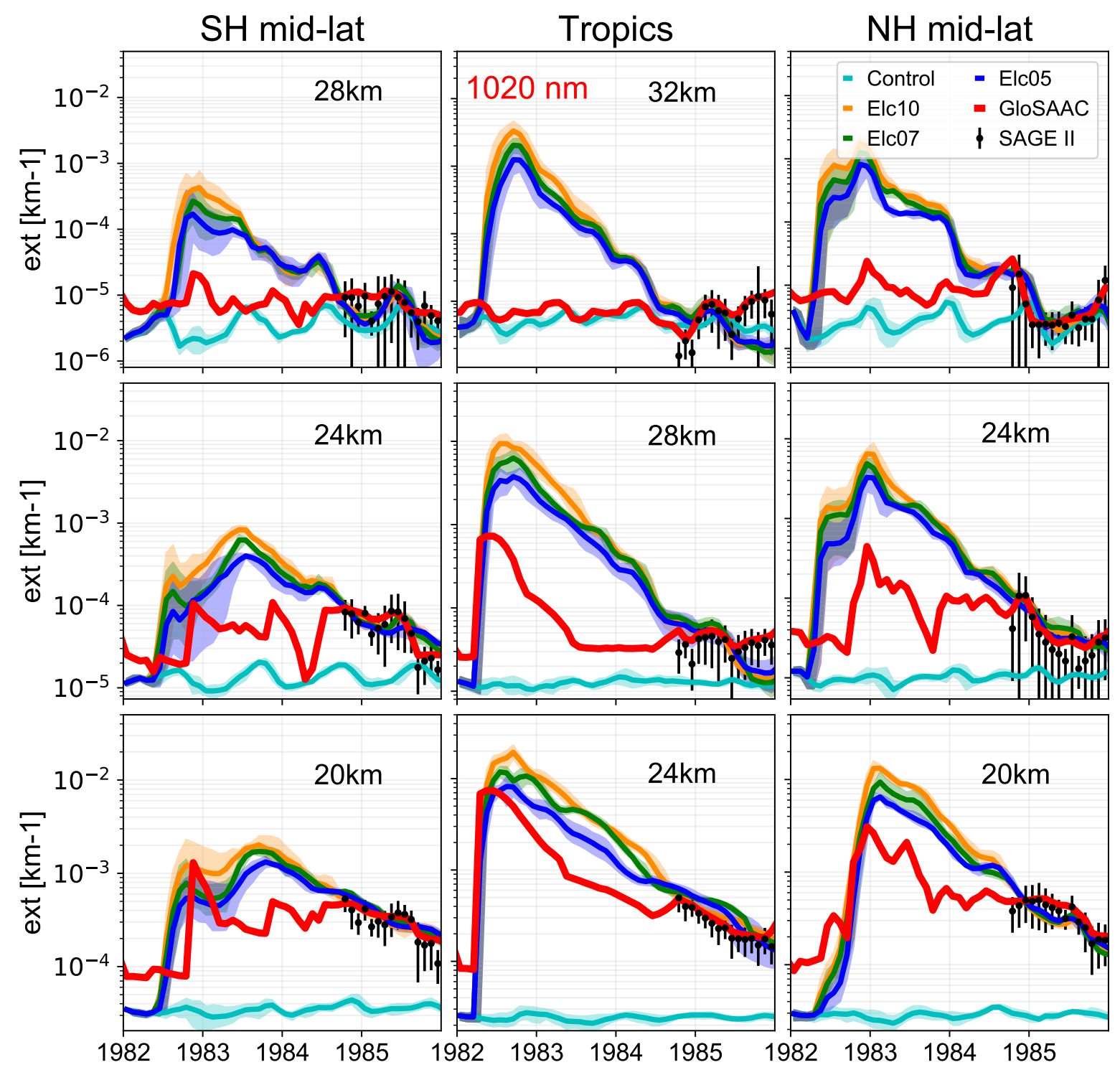

Figure S2. Same as Figure S1 but for the El-Chichon eruption 

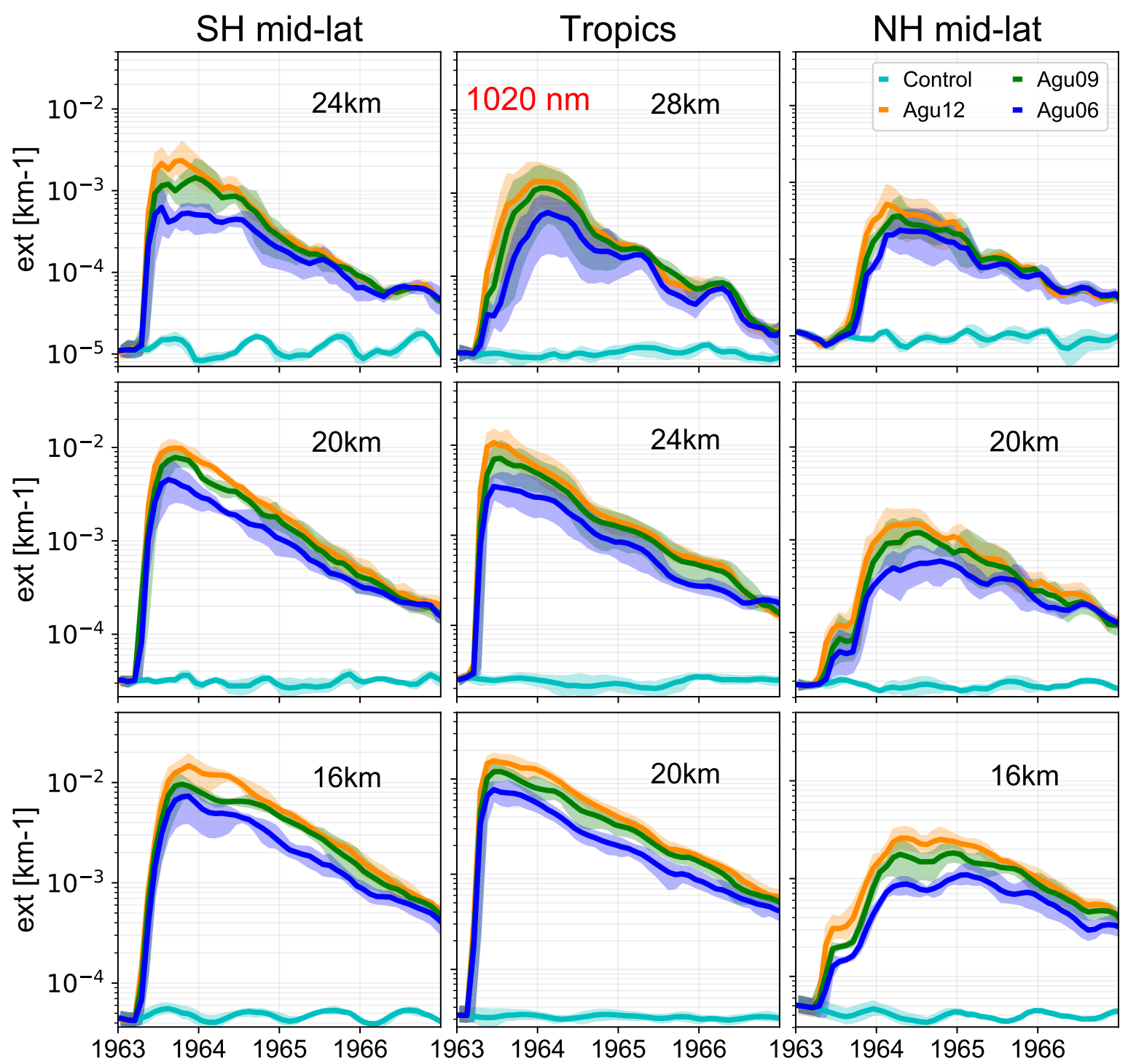

Figure S3. Same as Figure S1 but for the Agung eruption. Extinction at $1020 \mathrm{~nm}$ is not available in the evaluation datasets, hence only simulated extinctions are shown. 

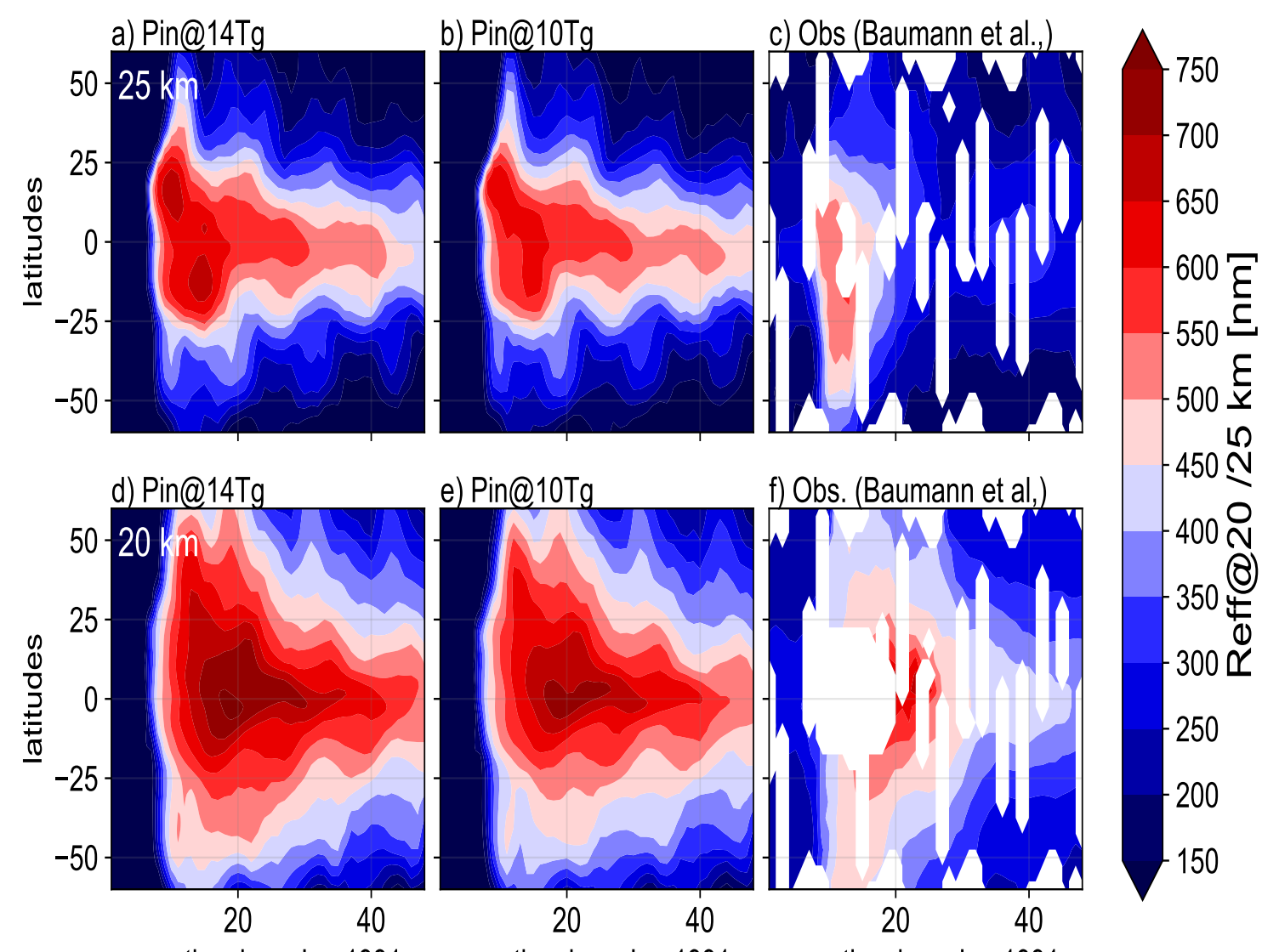

e) Pin@10Tg
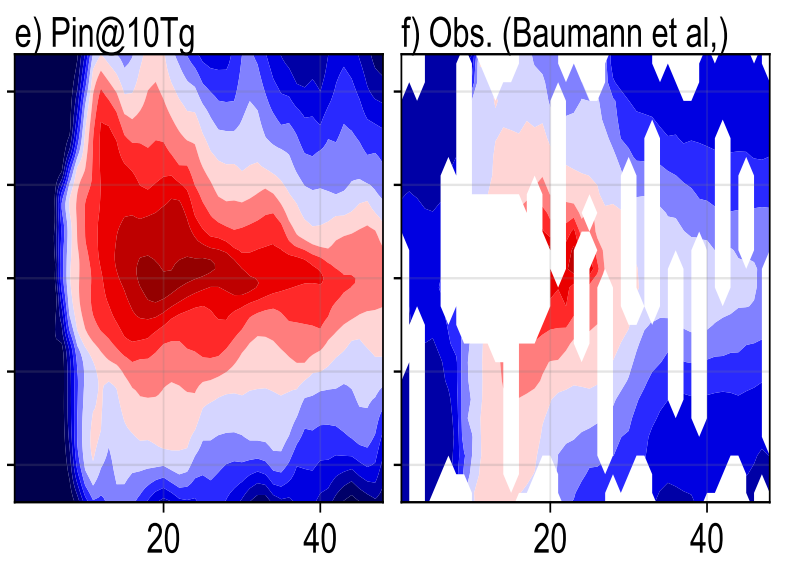

months since Jan 1991

Figure S4. Modelled (from simulations Pin14 and Pin20) and observation-derived (from (Bauman et al., 2003)) effective radii (Reff, in $\mu \mathrm{m}$ ) at (a)-(c) $25 \mathrm{~km}$ and (d)-(f) $20 \mathrm{~km}$. 